\title{
Training in Nigerian art schools: a critique of gender distribution
}

\author{
Johnson Adelani Abodunrin \\ Department of Fine and Applied Arts, \\ Ladoke Akintola University of Technology, Nigeria
}

Received: May 22, 2017. Revised: August 3, 2017. Accepted: September 6, 2017

\begin{abstract}
Training is indispensable in all facets of life in order to further knowledge and skills irrespective of gender difference, yet this disparity has become a phenomenon in artistic practice in Nigeria. The study aimed at examining art training in relation to gender distribution into various areas of specialization in art schools in Nigeria. There has been a gender imbalance in various areas of specialization which has left certain areas for male and female. Data for this study were collected in art School in Southwestern Nigeria between 2011/2012 to 2014/2015 academic sessions using archival materials to know the gender affinities. The university selected as sample size within the geographical scope of the study is Ladoke Akintola University of Technology, Ogbomoso. The selection was based on the orientation of their training and admission criteria which differs tremendously. Descriptive analysis was adopted to know the gender affiliation in the practice. Finding reveals that the total enrollments of students are more of females $(55.8 \%)$ than male $(45.2 \%)$ are admitted to study art. The result has also shown that more female $(93.3 \%)$ specializes in textile while more male (84\%) students are in sculpture. This perhaps could be attributed to the nature and the demands of each area of specialization. Textile design attracts more female artist because of; the socio-cultural affiliation of the discipline, interest in fashion; the readily available market for textile wares across all social class and the less demand on draughtsmanship skills as compared to other forms of arts.
\end{abstract}

Keywords: training; art school; gender; Nigeria

How to Cite: Abodunrin, J. A. (2017). Training in Nigerian art schools: a critique of gender distribution. Harmonia: Journal of Arts Research And Education, 17(2), 105-112. doi:http:/ / dx.doi.org/10.15294/harmonia.v17i2.9826

\section{INTRODUCTION}

Training generally, is an on-going process of teaching the basic skills to perform certain task effectively and efficiently. It focuses on teaching operational skills to the technical persons. The training program is arranged in order to provide basic knowledge and skill, especially for vocational training. The training arrangement involves systematic procedures that help to increase the knowledge and skills of the trainees to change in the environment. It develops the technical know-how so as to increase the operating skills for performing a specific job with proficiency. Therefore, it can be said that training refers to a systematic procedure designed to improve performance at the individual, group or organizational level.

In educational setting such as schools, training of different subjects' area is done

\footnotetext{
${ }^{\square}$ Corresponding author: P.M.B 4000, Ogbomosho Rd, Nigeria

E-mail: jaabodunrin@lautech.edu.ng
} 
to improve the technical skills of the participants such as in art practice. Art institutions are established to cater for various training in an area such as Painting, Sculpture, Textile, Graphics, Ceramics and other Art courses, with skill development and acquisition. As higher institutions were being set up in the country, the curriculum of each art School is tailored towards the aspiration of the society at large.

Prospective art Students are admitted into various art institutions in Nigeria having met the minimum requirements for admission into such institutions. At this level, gender distributions were not considered paramount; students are dispersed into their various course of choice depending on the nomenclature of such art school. The study is to examine gender distribution in Nigeria art schools with aim of looking at gender biases and specialization affinities and it is limited to painting specialization within the southwestern Nigeria. The university selected as sample size within the geographical scope of the study is Ladoke Akintola University of Technology, Ogbomoso. The selection was based on the academic orientation of their training and admission criteria which differs tremendously from any other institution in Nigeria (Yahaya, 2004).

The University, which started as a third generation university, and precisely as the number thirtieth (30) universities in Nigeria, grew rapidly in academic standards to become one of the best University in the country (National University Commission Report, 2003). Such phenomenal growth is largely attributable to the University's peculiar philosophy, academic orientation and the strength derived from joint ownership by the two states, as well as the geographical circumstance and context of the University's location.

The university runs Bachelor's degree, Postgraduate Diploma and Postgraduate degree in more than thirty (30) disciplines which include Fine and Applied Arts. Arising from all these academic programmes, the University currently enrolled over 26,000 students for its matriculati- on programmes and about 49,000 students the non-matriculation, the pre-degree programmes, the bachelor's' degree part-time programmes, and the postgraduate enrolment at the professional degree level (University Annual Report, 2010/2011). The university has enrolment pattern and criteria for admission that is unique to every discipline; this has made this study highly expedient.

\section{METHODS}

Primary data were collected through oral interview of various students of art in LAUTECH's Fine and Applied Art's department to know their perception towards the area of specialization and practice while the secondary data are the list of collation of specialized students between 2010 and 2015; a period of five years. The demographic data reveals five (5) consecutive sets of students; of whom three (3) sets have graduated, and two (2) sets are currently in 400 and 500 levels respectively. Data of students' enrolment into fine and Applied Arts between 2011/2012 to 2014/2015 academic sessions were collected using archival materials to know the gender affinities. This period recorded a large number of students' enrolment in LAUTECH's Fine and Applied arts. The selection is based on the location and the orientation of their training. The admission criteria were also considered paramount in this study. Qualitative and quantitative approaches are adopted through descriptive analysis which includes tabulations and cross-tabulations, percentages and pie-chart.

\section{Gender and Artistic Training in Nigeria}

Training for gender equality is a transformative process that aims to provide knowledge, techniques, and tools to develop skills and changes in attitudes and behaviors. It is a continuous and longterm process that requires political will and commitment of all parties in order to create inclusive societies that recognize the need to promote gender equality (Usha \& 
Toby, 2004). Training is offered in Schools through courses module and direction which is aimed at achieving specific goals at different levels of educational training. In Nigeria, Art curriculum is also developed to meet aspiration and intention of various art institutions without bias for gender affiliation. Gender is a broad analytical concept, which has grown out of attempts to understand the equality between men and women. The concept not only concerns women but also highlights women's roles and responsibilities in relation to those of men.

Various scholars have worked on issues relating to gender. According to UNESCO (2005), gender disparity in education is so central to the performance of the millennium development goals. Ekezie (1994) pointed out that through school enrolments in Africa have increased in the last few decades, girls' education still lags behind than that of boys especially after primary school. This is because an equal opportunity in male and female enrolment in schools is still far from being accomplished. In another study by UNESCO (2005), in a critical analysis of the data on female access to and participation in education shows that the situation is worst in the northern part of Nigeria, a situation which has been in existence for nearly a century with little improvement.

However, female artists have been involved in making art throughout history; their work often has not been as well acknowledged as that of men. Often, a certain area of specialization is associated with female artists such as textile arts (Nelson et al., 2005). Women's roles in relation to art, of course, vary in different culture and communities. Many art forms considered to be created predominantly by women have been historically dismissed from the art canon as a craft, as opposed to fine art which is widely studied by men. Women in Nigeria have had various challenges in order to obtain an equal education in all forms of formal education in Nigeria as education is identified to be a basic human right and has been recognized as such since 1948 through the adoption of the universal declaration on human rights.

The genesis of women in art in Nigeria can be traced to the traditional arts been engaged in the area of pottery, weaving and other craft works. Pottery has been described as one of the cheapest arts being practiced and heavily dominated by women, also women in Southern Nigeria are popularly known for cloth weaving or textile making, while this is mostly done by men in Northern Nigeria (Kriger, 1993). Similarly, in modern periods more women are found often in textile, graphics, and ceramics, except in few cases where they are involved in painting and sculpture, an example of such is Ndidi Dike and others, who are working in sculpture and mixedmedia.

The attempt of women in every aspect of visual training and practice will develop their interest in visual art, and provide unimpeded opportunities for the expression of their perspectives and reactions. With their involvement, new talent, new art forms, and the diversity of women who are exploring ways to express themselves through visual art.

The gender distribution in Nigeria from early education up till the highest levels of decision-making is to be taken seriously as it has created gender imbalance in the structure of events (Omoregie \& Abraham, 2009). This is not limited to the political structure alone, but to all aspect of human endeavor. In Nigeria art institutions, students are distributed to various departments on gaining the admission without attention to gender balance. This has enabled imbalance in gender distribution which later created for more participation of men or women in the certain profession.

\section{Art Training Curriculum In Nigeria}

Art curriculum was created to cater for the differences in talents opportunities and roles posed by or open to students after their graduation. To achieve this goal, various areas of the artistic practice were initiated to further knowledge and develop skills to cater for the aspiration of the 
society. In Nigeria art institutions, different nomenclatures were used to describe the nature of their training and the general orientation of their programs. Some art department uses fine art while others combine fine and applied arts or industrial and designs. Students have been admitted are subjected to different criteria for admission, some are purely science based or art subjects. This study looked at the enrollment, admission criteria and specialization of students in art with gender affinity in training and enrolment in the department of Fine and Applied Arts, Ladoke Akintola University of Technology, Ogbomoso.

The Department of fine and applied arts, LAUTECH was established to serve as an agency for artistic, cultural, technological and industrial development through research and modernization of indigenous art concepts and technology in relation to social, economic and cultural realities of the world. It was also to educate students with adequate academic background integrated with sufficient technological training necessary for the challenges of environmental development as well as management of cultural and industrial matters. The department was conceived to train the individual to acquire artistic skills in Painting, Sculpture, Ceramic, Graphic Design and Textile Design without a call for gender imbalance.

The admission criteria have been so unique that it accommodates science students' opportunity to study fine and applied arts; this is in no measure to improve the aesthetic and technological growth in the country. Admission to the first year is through the Joint Admissions and Matriculation Board's Unified Tertiary Matriculation (UTME). The prospective candidate must have a minimum of 5 credits passed at not more than two sitting at the Senior Secondary School Certificate level or its equivalent. Subjects must include English language, fine art/visual art, Mathematics and any two science subjects (FAA undergraduate Curriculum, LAUTECH)

The duration of the programme is five years for UME candidates and four years for the direct entry candidates. For the first one year, students are expected to offer the compulsory university courses, while they are given an intensive and broad-based exposure to the major areas of fine and Applied Arts in year two before going into a specialization in their third year. Students specialize in one of the following areas: Painting, Sculpture, Ceramics, Graphic design, and Textile design. Students are awarded the Bachelor of Technology (honours) degree in Fine and Applied Arts after completing the required courses which lasted for a minimum of five years (FAA undergraduate Curriculum).

\section{Nature and Demands of Faa Courses}

Visual art courses enable students to be capable of facing challenges that associates with an area of specialization in art. To ensure both breadth and depth of knowledge and understanding, the student must choose one area of specialization from the available areas, depending on the School. In LAUTECH, students specializing in 300level having been exposed to the general arts at 200level; they specialize in the following areas: Painting, Sculpture, Ceramics, Graphic design, and Textile design. Each of this has its own peculiarities of forms which differentiate them from the other. Painting, for example, is the art of creating pictures by applying colour to a surface. It can record events; capture a likeness of a person, place, or object; tell stories; decorate walls; illustrate texts. Paintings can express emotions and ideas, or simply be enjoyed for their beauty. Painting is also a mode of creative expression, and the forms are numerous among other aesthetic modes, may serve to manifest the expressive and conceptual intention of the practitioner. The forms of painting can be in the use of media, subject matter, and styles. The media are the vehicle used in achieving the expressive quality such as water colour, oil colour, acrylic, pastel (both chalk and oil) and others. Each of this medium has different peculiarities which make the masonry of the medium. Subject matter suggests the intention or 
goal of the painting which could be in form of still-life, landscape, nature, figural and non-figural expression while styles represent the pattern of expression which is constant and reoccurring. It can be naturalistic, expressive, realistic, abstraction, stylization, cubism and various other ways of representation. These forms of painting require competence which makes the discipline exclusively restricted.

Painting is one of the art forms that are taught in most of the Nigerian art schools and the criteria for studying it is seen in the interest and competence displayed by each student. Student shows interest and competence in the enrollment and distribution into this particular area of specialization.

Textile Design is essentially the process of creating designs for woven, knitted or printed fabrics. Textile designers are involved with the production of these designs, which are used sometimes repeatedly. It also involves various techniques of batik tie and dye; the production of decorative textile materials and designs for use in homes and public places. Graphic design, also known as communication design, is the art and practice of planning and projecting ideas and experiences with visual and textual content. The form of the communication can be physical or virtual and may include images, words, or graphic forms. The experience can take place in an instant or over a long period of time. The work can happen at any scale, from the design of a single postage stamp to a national postal signage system, or from a company's digital avatar to the sprawling and interlinked digital and physical content of an international newspaper. It can also be for any purpose, whether commercial, educational, cultural, or political.

Sculpture, an artistic form in which hard or plastic materials are worked into three-dimensional art objects. The designs may be embodied in freestanding objects, in reliefs on surfaces or in the environment. An enormous variety of media may be used, including clay, cement, wax, stone, metal, fabric, wood, plaster, rubber and found objects.

Ceramics are classified as inorganic and nonmetallic materials that are essential to our daily lifestyle. This category of materials includes things like tile, bricks, plates, glass, and toilets ware. All these areas with their peculiarities and nature are studied in different art schools by both male and female.

\section{RESULTS AND DISCUSSION}

The total number of students enrollment within 2010 and 2015 is 385 out of which $215(55.8 \%)$ students are female while $170(44.2 \%)$ are male. This shows that more of female are admitted to study fine and applied arts in LAUTECH which is an indication that the admission criteria favors the intakes of female students into the department (Table 1-5). While distribution into various areas of specialization indicates that $153(40 \%)$ students specialized in graphics, 119 (31\%) in textile, $57(15 \%)$ in painting, $31(8.1 \%)$ in ceramic and $25(6.1 \%)$ in sculpture respectively (Figure 1). This is a hint that majority of the students in the department are interested in studying graphics while painting, ceramics, and sculpture are for a limited number of students as been shown in the finding. Also, gender distribution were measured in this study and it was indicated that $45(78 \%)$ students are male while $12(21.1 \%)$ are female in painting; graphics recorded $83(54.2 \%)$ male and $70(45.8 \%)$ female, while textile have $8(6.7 \%)$ male and 111 (93.3\%) female, sculpture is $21(84 \%)$ male with $4(16 \%)$ female and ceramics is 13 (41.9) male and 18 (58.1\%) female (Figure 1). This however shown that more female specializes in textile and graphics while more male students are in sculpture and painting. This perhaps could be attributed to the nature and the demands of each area of specialization. Textile attracts more female artist because of; the socio-cultural affiliation of textile with women artist; the high level of interest in fashion; the readily available market for textile wares across all social class and the less demand 
on draughtsmanship skills as compared to other forms of arts.

Table 1. Distribution of Students by specialization and Gender Affinities in Painting

\begin{tabular}{ccccc}
\hline S/N & Session & \multicolumn{3}{c}{ Painting } \\
\hline 1 & $2010 / 2011$ & $10(76.9)$ & $3(23.1)$ & 13 \\
2 & $2011 / 2012$ & $4(80)$ & $1(20)$ & 5 \\
3 & $2012 / 2013$ & $13(86.7)$ & $2(13.3)$ & 15 \\
4 & $2013 / 2014$ & $6(60)$ & $4(40)$ & 10 \\
5 & $2014 / 2015$ & $12(85.7)$ & $2(14.3)$ & 14 \\
& Total & $45(78.9)$ & $12(21.1)$ & 57 \\
\hline
\end{tabular}

Source: Author's Fieldwork (2017)

Table 2. Distribution of Students by specialization and Gender Affinities in Graphics

\begin{tabular}{|c|c|c|c|c|}
\hline $\mathrm{S} / \mathrm{N}$ & Session & \multicolumn{3}{|c|}{ Graphics } \\
\hline & & $\mathrm{M}(\%)$ & $\mathrm{F}(\%)$ & $\mathrm{T}$ \\
\hline 1 & $2010 / 2011$ & $6(46.2)$ & $7(53.8)$ & 13 \\
\hline 2 & $2011 / 2012$ & 13 (56.5) & $10(43.5)$ & 23 \\
\hline 3 & $2012 / 2013$ & $21(72.4)$ & 8 (27.6) & 29 \\
\hline 4 & $2013 / 2014$ & $22(52.4)$ & $20(47.6)$ & 42 \\
\hline 5 & $2014 / 2015$ & $21(45.7)$ & $25(54.3)$ & 46 \\
\hline & Total & $83(54.2)$ & $70(45.8)$ & 153 \\
\hline
\end{tabular}

Table 3. Distribution of Students by specialization and Gender Affinities in Textile

\begin{tabular}{ccccc}
\hline S/N & Session & \multicolumn{3}{c}{ Textile } \\
\hline & & $\mathrm{M}(\%)$ & $\mathrm{F}(\%)$ & $\mathrm{T}$ \\
\hline 1 & $2010 / 2011$ & $1(20)$ & $4(8)$ & 5 \\
2 & $2011 / 2012$ & $1(12.5)$ & $7(87.5)$ & 8 \\
3 & $2012 / 2013$ & $1(4.3)$ & $22(95.7)$ & 23 \\
4 & $2013 / 2014$ & $0(0)$ & $43(100)$ & 43 \\
5 & $2014 / 2015$ & $5(12.5)$ & $35(87.5)$ & 40 \\
& Total & $8(6.7)$ & $111(93.3)$ & 119 \\
\hline
\end{tabular}

Source: Author's Fieldwork (2017)
Table 4. Distribution of Students by specialization and Gender Affinities in Sculpture

\begin{tabular}{ccccc}
\hline S/N & Session & \multicolumn{3}{c}{ Sculpture } \\
\hline & & $\mathrm{M}(\%)$ & $\mathrm{F}(\%)$ & $\mathrm{T}$ \\
\hline 1 & $2010 / 2011$ & $2(100)$ & $0(0)$ & 2 \\
2 & $2011 / 2012$ & $5(83.3)$ & $1(16.7)$ & 6 \\
3 & $2012 / 2013$ & $6(85.7)$ & $1(14.3)$ & 7 \\
4 & $2013 / 2014$ & $4(80)$ & $1(20)$ & 5 \\
5 & $2014 / 2015$ & $4(80)$ & $1(20)$ & 5 \\
& Total & $21(84)$ & $4(16)$ & 25
\end{tabular}

Source: Author's Fieldwork (2017)

Table 5. Distribution of Students by specialization and Gender Affinities in Ceramics

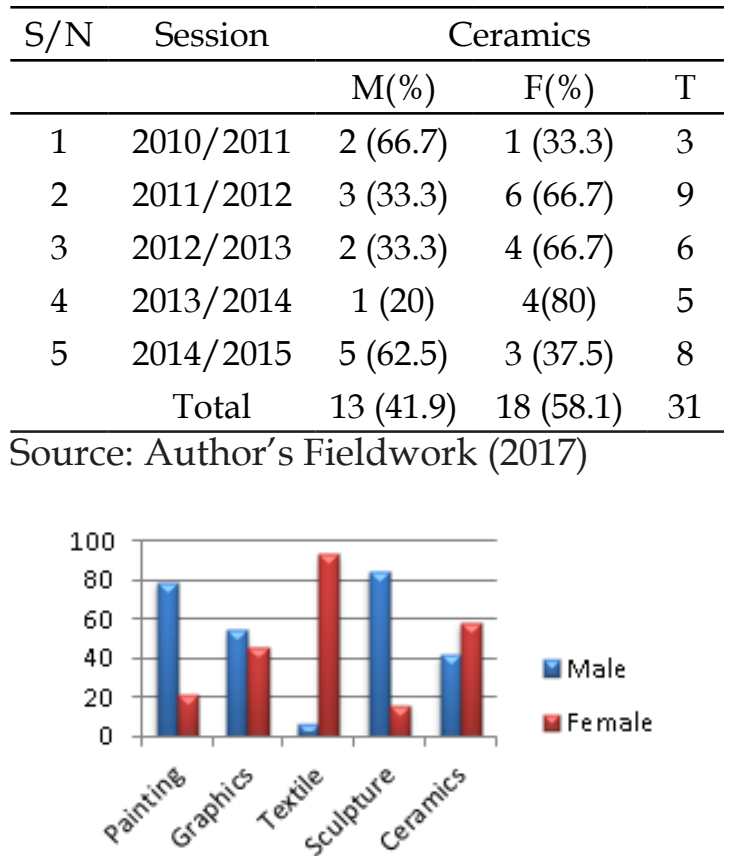

Figure 1. Total Student Enrolment in Fine and Applied Arts (LAUTECH). Source: Author's Fieldwork (2017)

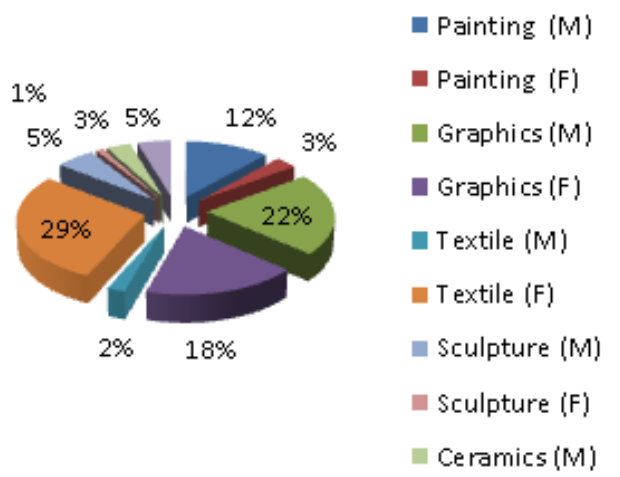

Figure 2. Gender Distribution in Fine and Applied Arts (LAUTECH). Source: Author's Fieldwork (2017) 


\section{CONCLUSION}

Based on the findings of the study, more females are admitted to study fine and applied arts in LAUTECH between 2010/ 2011 and 2014/2015 academic session with a high number of them specialized in textile design. It was also discovered that the gender distribution in Nigeria from early education up till the highest levels of decision-making is to be taken seriously as it has created gender imbalance in the structure of events. Art as a field of study has not been left out in this occurrence with certain areas of specialization dominated by a particular sex. On the account of the foregoing that this study recommends that any category of students can specialize in any field of arts and that no area of specialization has been designed for gender bias, therefore, prospective students can cope or succeed in any field of their interest.

\section{REFERENCES}

Archival Materials - Examination and Records, Fine and Applied Art Department, Ladoke Akintola University of Technology, Ogbomoso, Oyo State, Nigeria.

Annual Report. (2010/2011). The Reawakening. Nigeria: Ladoke Akintola University of Technology Ogbomoso.

Ekezie, A. I. (1994). The role of evaluation and research in competent agricultural educator preparation in Nigeria. Studies in Educational Evaluation, 20(2), 201-206.

Kriger, C. (1993). Textile Production and Gender in the Sokoto Caliphate. The Journal of African History, 34(3), 361401.

Nelson, N. J., LaBat, K. L., \& Williams, G. M. (2005, August). More than 'just a little hobby': Women and textile art in Ireland. Women's Studies International Forum, 28(4), 328-342.

Omoregie, N., \& Abraham, I. O. (2009). Persistent gender inequality in Nigerian education. Delta, 18(301), 450-
786.

UNESCO. (2005). Dealing with Gender Issues in Nigeria Colleges of Education. Afri J. Paris, (1), 15-20.

Undergraduate Curriculum- Fine and Applied Art Department, Ladoke Akintola University of Technology, Ogbomoso, Oyo State, Nigeria.

Usha, V. \& Toby M. (2004). Training and Development: An Examination of Definitions and Dependent Variables. The Academy of Human Resource Development International Conference. (AHRD) (Austin, TX, Mar 3-7, 2004) p 850-857 (Symp. 39-2)

Yahaya, L. A. (2004). Disparity in enrolment of male and female undergraduates in science and technology based faculties at university of Ilorin: Implication for counselling. Nigeria Journal of Counselling and Applied Psychology, 2(1), 186-201.

\section{Oral Interview}

Abina, J. (2017). Personal Communication; Painting Specialization; 400 level, LAUTECH.

Alagbede, B. (2017). Personal Communication; Painting Specialization; Graduate, LAUTECH.

Alli, A. (2017). Personal Communication; Painting Specialization; Graduate LAUTECH.

Adekunle, D. (2017). Personal Communication; Painting Specialization; 400level, LAUTECH.

Adekunle, T. (2017). Personal Communication; Painting Specialization; Graduate, LAUTECH.

Adeyemo, E. (2017). Personal Communication; Painting Specialization; 300 level, LAUTECH.

Ayobami, A. (2017). Personal Communication; Textile Specialization; 300 level, LAUTECH.

Bunmi, A. (2017). Personal Communication; Textile Specialization; Graduate LAUTECH.

Fetuga, A. (2017). Personal Communication; Textile Specialization; 300 level, LAUTECH. 
Igbayilola, W. (2017). Personal Communication; Painting Specialization; 400 level, LAUTECH.

Mpamah, C. (2017). Personal Communication; Textile Specialization; 400 level, LAUTECH.

Omola, D. (2017). Personal Communication; Painting Specialization; Graduate, LAUTECH.

Ogunlama, B. (2017). Personal Communication; Textile Specialization; 400 level, LAUTECH.

Owoade, I. (2017). Personal Communication; Painting Specialization; 400 level, LAUTECH.

Oyedele, A. (2017). Personal Communication; Sculpture Specialization; 400 level, LAUTECH.

Oyesanmi, F. (2017). Personal Communication; Ceramics Specialization; 300 level, LAUTECH.

Roselyn, B. (2017). Personal Communication; Graphics Specialization; 500 level, LAUTECH.

Sharaibi, D. (2017). Personal Communication; Graphics Specialization; 500 level, LAUTECH.

Temileyi, O. (2017). Personal Communication; Textile Specialization; 500 level, LAUTECH.

Tolulope, K. (2017). Personal Communication; Graphics Specialization; 300 level, LAUTECH. 